\title{
Physiological measurements of drawing and forming activities
}

\author{
Leinikka, Marianne
}

Design Research Society

2016-06

Leinikka , M , Huotilainen , M , Seitamaa-Hakkarainen, P , Groth , C , Rankanen , M \& Mäkelä, M 2016 , Physiological measurements of drawing and forming activities . in P Lloyd \& E Bohemia (eds) , Proceedings of DRS2016: Design + Research + Society -

Future-Focused Thinking . vol. Volume 7 , Proceedings of DRS , vol. 2016 , Design Research Society, London , pp. 2941- 2958 , Design Research Society International Conference, Brighton, United Kingdom , 27/06/2016 .

http://hdl.handle.net/10138/232751

cc_by_nc

publishedVersion

Downloaded from Helda, University of Helsinki institutional repository.

This is an electronic reprint of the original article.

This reprint may differ from the original in pagination and typographic detail.

Please cite the original version. 


\title{
Physiological measurements of drawing and forming activities
}

\author{
Marianne Leinikka ${ }^{a}$, Minna Huotilainen ${ }^{a, b}$, Pirita Seitamaa-Hakkarainen ${ }^{c}$, Camilla Groth $^{\mathrm{d}^{*}}$, \\ Mimmu Rankanen ${ }^{d}$, Maarit Mäkelä ${ }^{d}$ \\ ${ }^{a}$ Finnish Institute of Occupational Health \\ ${ }^{b}$ University of Helsinki, CICERO Learning Network \\ 'University of Helsinki, Department of Teachers' Education \\ ${ }^{d}$ Aalto University, School of Arts, Design and architecture, Design department \\ *Corresponding author e-mail: camilla.groth@aalto.fi
}

\begin{abstract}
The embodiment of tools and experiential knowledge of materials gained over time lies at the heart of both design and craft practices. However, empirical studies combining the study of mind and body in relation to design and craft practice is in its infancy. In the Handling Mind project, we conducted psychophysiological experiments in order to illuminate the relationships between making and feeling, handling creative situations and the embodied mind in thirty participants, both students and professionals representing expertise in various design fields, working with visual (drawing) or material (forming clay) tasks of 1) copying, 2) creating novel designs, or 3) freely improvising. Our findings highlight both the importance of the embodiment with respect to the material and the different physiological states observed in tasks differing in requirements related to following orders or creativity. We conclude that the embodied activities are both supported and altered by bodily and mental processes.
\end{abstract}

Keywords: Design research, Neuroscience, Forming, Drawing

\section{Introduction}

Research on design cognition can benefit from methods from cognitive neuroscience (Seitamaa-Hakkarainen et al. 2014). There is extensive neuroscientific research related to embodiment and motor activities, and these studies have analysed how motor processes are connected to cognitive functions. In a previous article (Seitamaa-Hakkarainen et al. 2014), we have described the possibilities and challenges of utilising neuroscientific research 
methods when studying design and making processes. This present study addresses relations between reproduction and innovation. In this paper, we report our results from the psychophysiological experiments that analysed how designers handle different creative situations and how materials affect their embodied processes. We are particularly interested in how drawing and forming clay differ when carrying out tasks involving copying, creating novel designs or free improvisation.

The present study relies on the multidisciplinary research project 'Handling Mind: Embodiment, Creativity and Design', which is one of 12 projects in the Human Mind research call given by the Academy of Finland. The project is conducted by a research consortium that includes Aalto University, the University of Helsinki, and the Finnish Institute of Occupational Health. This multidisciplinary research project aims to provide a bridge between the areas of neuroscience, psychology, design and educational research that are concerned with embodied activities, social creativity and the expanded nature of the human mind. Through four interlinked study tracks, we examine how participation in creative activities associated with crafts and design affects the participants' socio-emotional experiences and the nature of the associated embodied knowing, with a focus on the interaction between mind, body and materials.

Designing and making are multimodal processes that require complex problem-solving processes as well as hand, mind and eye co-ordination. They are based on the extensive use of various embodied senses, tactual, and sensor-motoric operations. Studies indicate that practitioners' senses never operate on their own, but are always interrelated with one another (Gallace \& Spence 2008). Using a variety of neurophysiological and neuroimaging methods, the neural mechanisms involved in perception or observation of motor activities have been intensely studied for two decades (for a review, see Rizzolatti \& Craighero 2004). These studies have revealed activation of the sensor motor areas of the brain as a response stimulus of seeing other people working (Borghia \& Cimattic 2010) or seeing hand-held tools (Witt et al. 2010). However, empirical studies that combine the study of mind and body in relation to design and craft practice are still extremely rare. Including the measurement of different physiological signals such as electrocardiogram, skin conductance, movement or brain activations in experimental setups hold great promise for a deeper understanding of these embodied actions.

Only recently, some neuroscientific studies have been published that analyse the effects of drawing on alpha activity (Belkofer et al. 2014) and compare brain activity during drawing and sculpting (Kurk et al. 2014). These studies used EEG to examine the brainwave frequency patterns of participants engaging in art-making. In general, non-event-locked physiological and brain activity is represented in patterns of specific activity related to cognitive processes and in response to any stimuli present in the environment. Theta waves are shown to be related to imaginative states and creative processes. Alpha waves are revealed in relaxed 
and normal conscious awareness, and beta waves are expressed during active thought and alert states. Gamma waves are correlated with cross-modal stimulus integration, synthesis, and information-rich processing (Luck 2005).

A previous study by Kurk et al. (2014) revealed that both clay forming and drawing increased gamma power in the right medial parietal lobe compared to general movement. Further, clay forming decreased right medial frontal gamma power and elevated theta power. Also, the study by Belkofer et al. (2014) indicated that alpha rhythm may play an important role in drawing. In other words, drawing and forming clay appear to be information-rich activities requiring simultaneous cognitive processing; however, drawing may provide a more relaxed state.

The role of human creativity is a pivotal aspect in studies of designing. In the present study, we were interested in creating an experimental setting suited both for psychophysiological and neuroscientific measuring and with which we can compare how designers deal with differently framed tasks. In addition to comparing distinct tasks, we focus especially on the differences between the materials provided. Defining the role of the provided materials for mental functions is clarified when we proceed to the next phase of our research setting and conduct neuroscientific measurements. In the current paper, we focus only on the psychophysiological measurements.

\subsection{Embodied making}

The mind has traditionally been researched separately from the body (Lakoff \& Johnson $1999,4)$. However, it has now become generally accepted that the mind is highly affected by the actions and experiences of the body, and vice versa (Hari \& Kujala 2009). Cognitive, sensory motor, emotional and social aspects are all included when creating something new with the hands.

The theory on embodied cognition (Merleau-Ponty 1962/2010; Varela et al. 1991; Noë 2004, 2009; Lakoff \& Johnson 1999; Johnson 1987, 2007) includes the perceiving body in sense making and claims that human cognition is dependent upon its interaction with its environment, thus pointing at action and perception as keys in knowledge formation. Furthermore, studies in neuroscience have revealed that not only is the body relevant in making sense of the world, but it also affects our emotions and consequently our decisionmaking processes (Damasio 1994, 1999). Embodied cognition theory is also beginning to change the way research paradigms are constructed in cognitive science, taking into account the full organism-environment system and the situated and embodied nature of human cognition (Hari \& Kujala 2009, 1).

It has become relevant to address issues of the embodied mind in design studies, too, as design action and design cognition become closely linked through enactive thinking (Varela et al. 1991). Drawing as a thinking tool for designers has been rigorously studied (Goel 1995; 
Seitamaa-Hakkarainen \& Hakkarainen 2004; Cain 2010; Kantrowitz et al. 2011), and particularly the field of interaction design and human computer interaction has taken on the philosophical strand of embodied cognition (Dourish 2001; Hornecker \& Buur 2006; Hornecker 2005; Höök 2010; Trotto \& Hummels 2013; Hummels \& Van Dijk 2015). However, relatively few have touched this issue within general design or craft research (for examples, see Poulsen \& Thorgensen 2010; Rompay \& Ludden 2013; Patel 2008). In learning a craft skill, the embodiment of tools and methods and the experiential knowledge of materials gained over time are pivotal and lies at the heart of both design and craft practices.

The aim of the present study was to research embodiment via measuring physiological reactions during design processes while drawing and forming clay. By using heart rate variability (HRV) derived signals during the entire experiment, we expected to track not only the participant's physiology, but also related mental states such as vigilance, attention span, the stress experienced and state of flow. Heart rate variability parameters are good indicators of the balance between the conscious central nervous system activities and the sympathetic and parasympathetic nervous system activations including the demands of physical activity (Veltman \& Gaillard 1998).

Increased mental stress leads to the activation of the sympathetic nervous system and an almost simultaneous withdrawal of the parasympathetic nervous system. Several time- and frequency-domain parameters reflect these activities in detail (see Results). Previous studies (Cinaz et al. 2010) have shown that several HRV parameters are good measures to track the interaction between cognitive and physiological processes. The underlying hypothesis in such studies is that the cardiac activity shows detailed reactions to any mental or physical activity, consequently also during the creative process.

The hypothesis is linked to the controversial discourse around the theories proposing that the way one thinks and feels is strongly influenced by feedback from the body. In our research, we follow the study line by Dunn et al. (2010), who showed in their recent study that cognitive-affective processing relates significantly to bodily responses. During the study, they showed affective images and recorded the participants' heart rate (HR) to measure what their bodily response to the images was. In their study, Herbert et al. (2010) applied the same method. As they point out, cardiac activity is closely related to emotional experience and the sensitivity of cardiac signals can easily be measured.

The specific research question for our study is: How do drawing and forming clay differ in tasks of copying, creating novel design or free improvisation with respect to different timings in creating physical and mental stress, frustration, or flow? This is the first experiment in which the effects of materials (especially important for the embodiment experience) are combined with the effects of the mental requirements of different creative tasks (copying, design, improvisation), and it lays a basis for future investigations in this field. 


\section{Methods}

Thirty participants, both students and professionals, representing expertise in various design fields participated in our study. They performed different drawing and clay forming tasks while wearing portable sensors (Faros, Mega Electronics, Finland) capable of recording the full electrocardiogram and accelerometers (Actigraph, GENEActiv, Finland) on their both wrists for hand movement detection (see Figure 1). All the measurements were conducted over the period November 2014 to March 2015 at the Aalto University, School of Art, Design and Architecture. The study had the ethical approval of the Institute of Behavioural Sciences of the University of Helsinki.

The study was a $2 \times 3 \times 2$ protocol with 2 different materials, 3 different tasks and 2 different timings, see details below and in Figure 2.

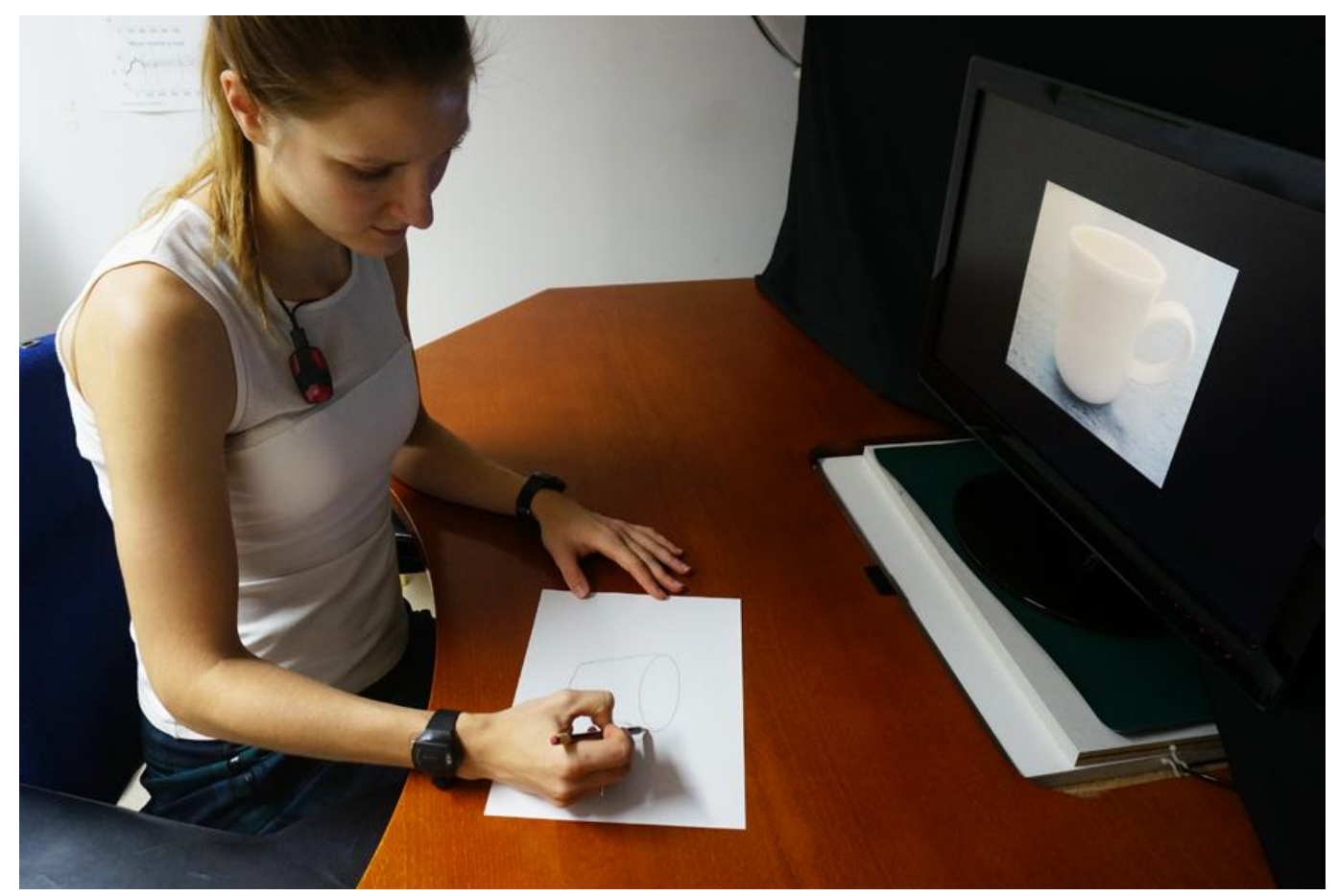

Figure 1. Participant wearing the measurement devices: Faros cardiac signal recording on the chest and Actigraph accelerometers on the wrists. Photo by Camilla Groth. 

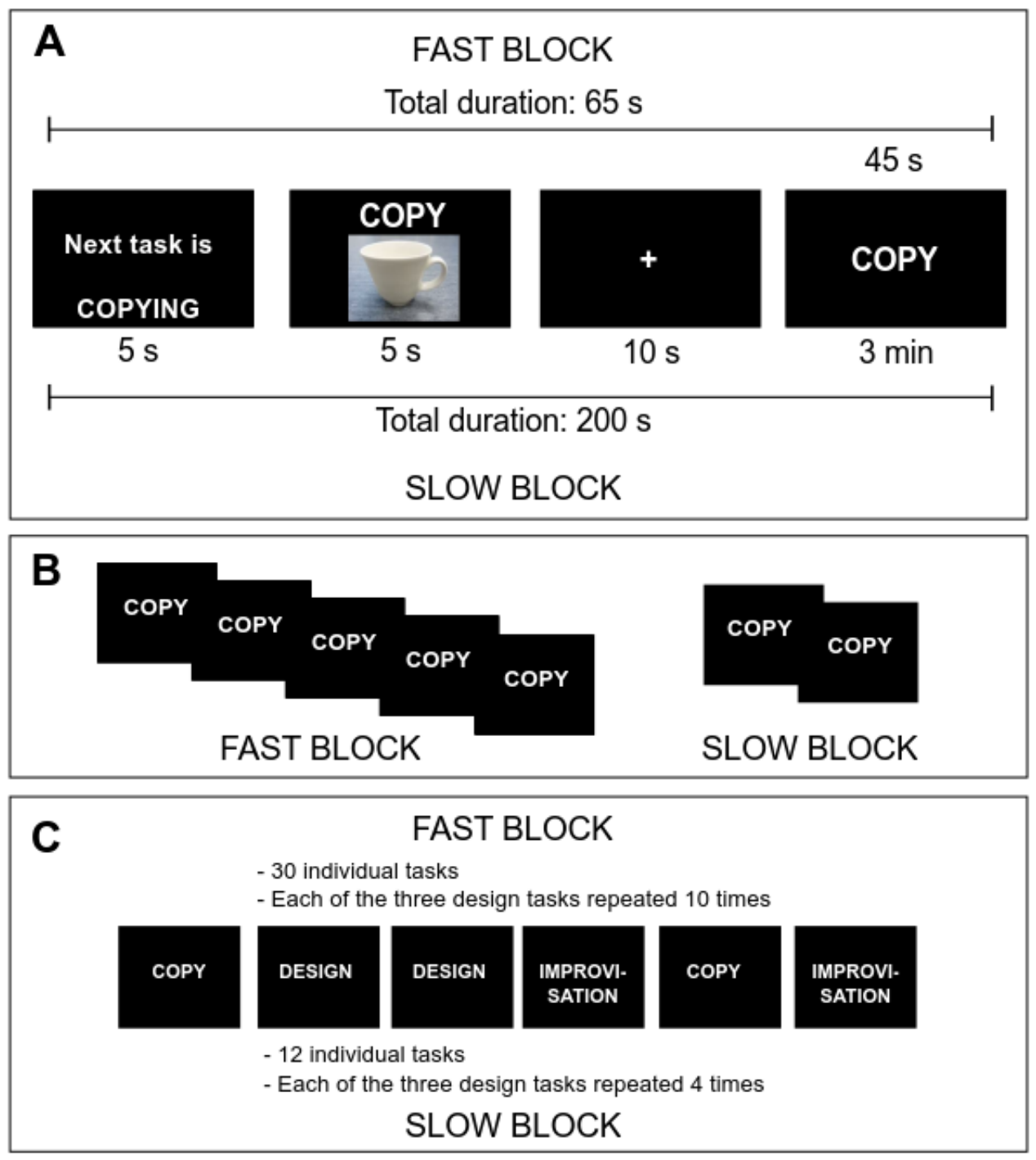

Figure 2. Experimental setting of the study. Panel A shows the timing of one task in the fast and slow blocks, panel B shows the replications of tasks in the fast and slow blocks, and panel $C$ shows the composition of both whole blocks. Figure by Marianne Leinikka.

In the study, each of the three design tasks were approached by both drawing with a pen on paper and by forming clay. The three design tasks in the experiments were 1) a copying task - drawing a copy of a cup on paper or forming it from clay on the basis of a photograph of a cup, 2) a design task - creating a new design for a cup by either drawing or forming, and 3) a free improvisation task - a creative work on a self-chosen topic by drawing or forming clay according to personal ideas or imagination.

The tasks of the study were executed with two different timing setups: fast and slow blocks, meaning that participants had either a short or a longer time to perform the required tasks during that particular block. Both fast and slow blocks were performed using both drawing 
and clay forming modalities and comprised each of the three tasks: copying, designing and improvising. Thus, each participant performed four blocks: fast and slow drawing blocks as well as fast and slow clay-forming blocks.

The participants executed the tasks according to the timing and instructions presented on a computer screen. Prior to actual drawing or forming clay task, the participants were first shown a 5-second-long instruction on the upcoming task (i.e. "Next task is ..."). Thereafter, the participants had 5 seconds to look at a picture of the cup (see Figure 3 ) and 10 seconds of an empty screen with a fixation cross to plan their work without moving. Finally, the actual drawing or clay forming started. In the fast block, the time available for drawing or forming was restricted to 45 seconds, whereas in the slow block, the time was 3 minutes. Therefore, in the fast block, one task (copy, design or improvise) lasted 65 seconds in total and in the slow block, 200 seconds, respectively. In all three tasks (copy, design and improvise), the participants were shown a picture of a cup as a stimulus, even though in the free improvisation task, the creative process was not limited in any way to the production of a cup.
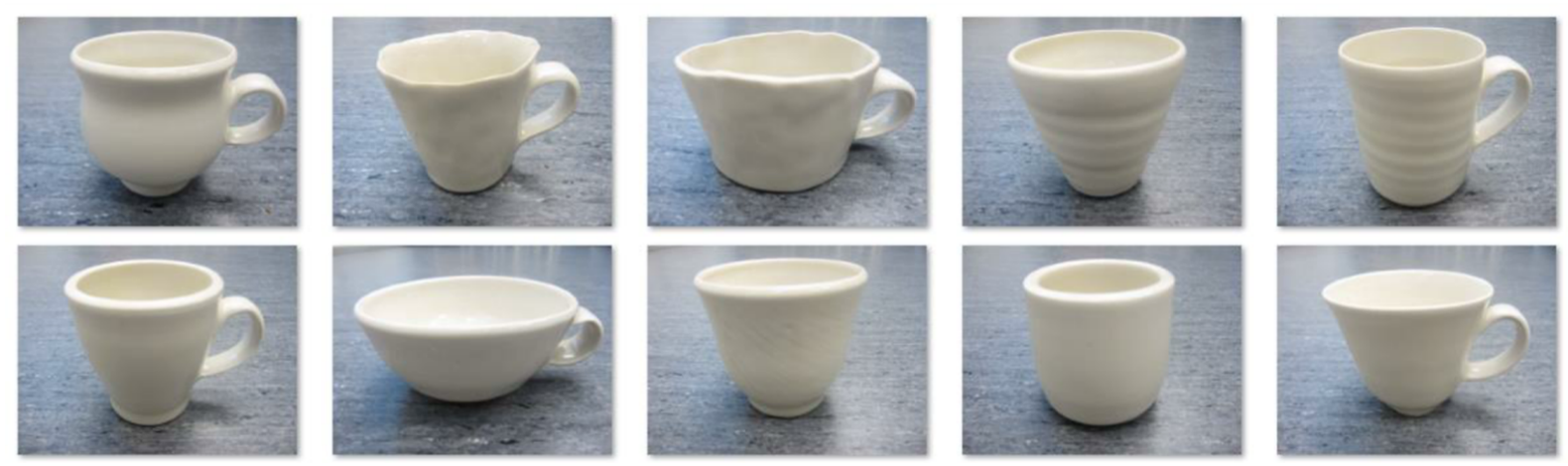

Figure 3. The cups presented as stimuli in the study. Photo by Marianne Leinikka. Cups made by Camilla Groth.

In both the clay forming and drawing modalities, the fast block consisted of 30 separate tasks following each other in a forced-paced manner. In order to have a sufficient duration of physiological data, each task was repeated five times in a row, and these sets of five were repeated twice. Therefore, each of the three different tasks was repeated ten times in the fast block. In the slow block, there were 12 separate tasks, and each task was repeated twice, thus yielding four presentation times for each of the three tasks. The order of each block and each task was randomised across the participants to minimise the effects of novelty (first blocks) and fatigue (towards the last blocks). At the beginning of the study, the participants had the opportunity to practise all three tasks, both drawing and forming clay, and both timings. At the end of the study, each participant had made 84 pieces of design (see Figures 4 and 5). 


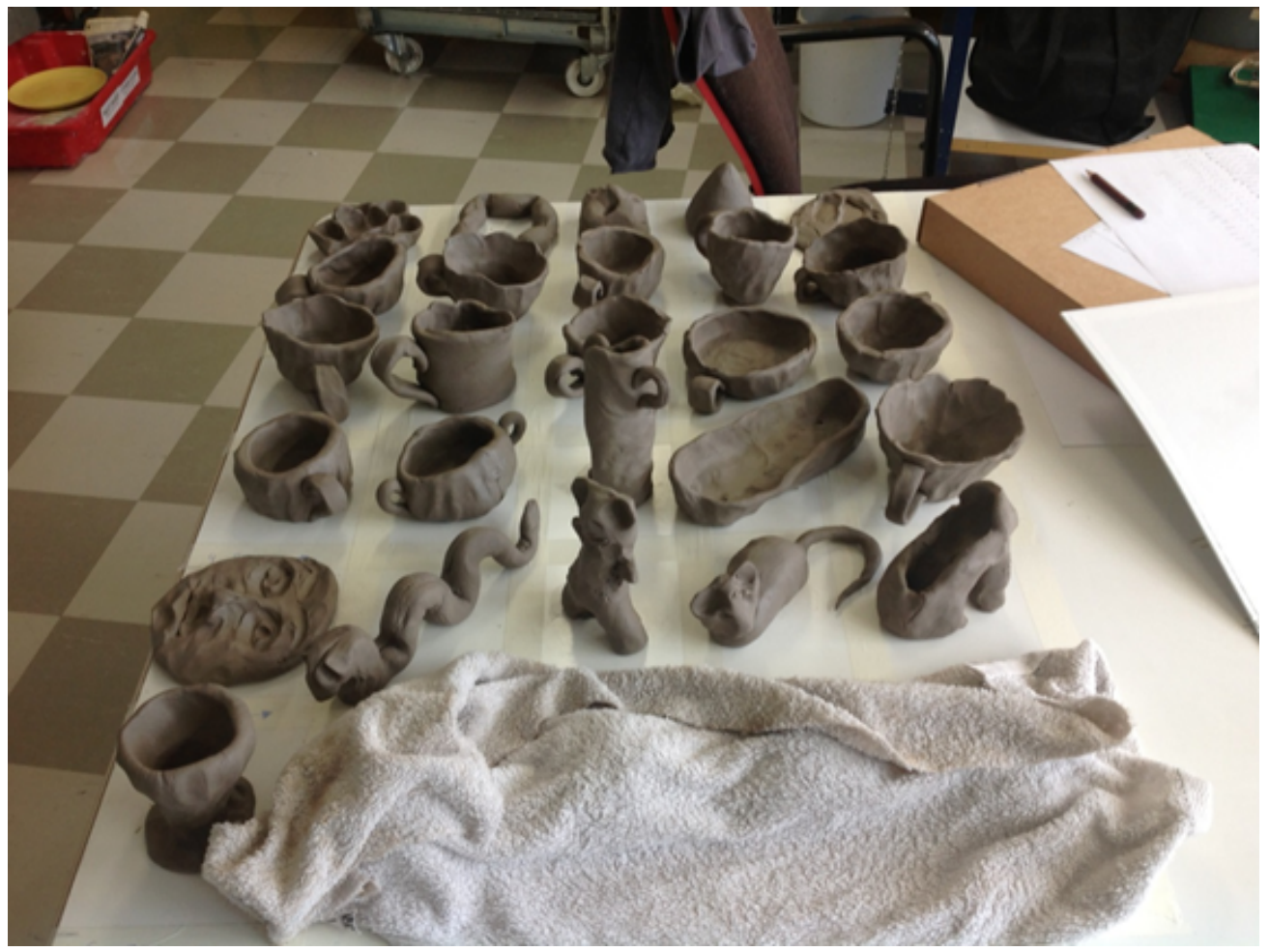

Figure 4: Newly made clay objects according to the mixed copying, designing and improvisation tasks. Photo by Marianne Leinikka.

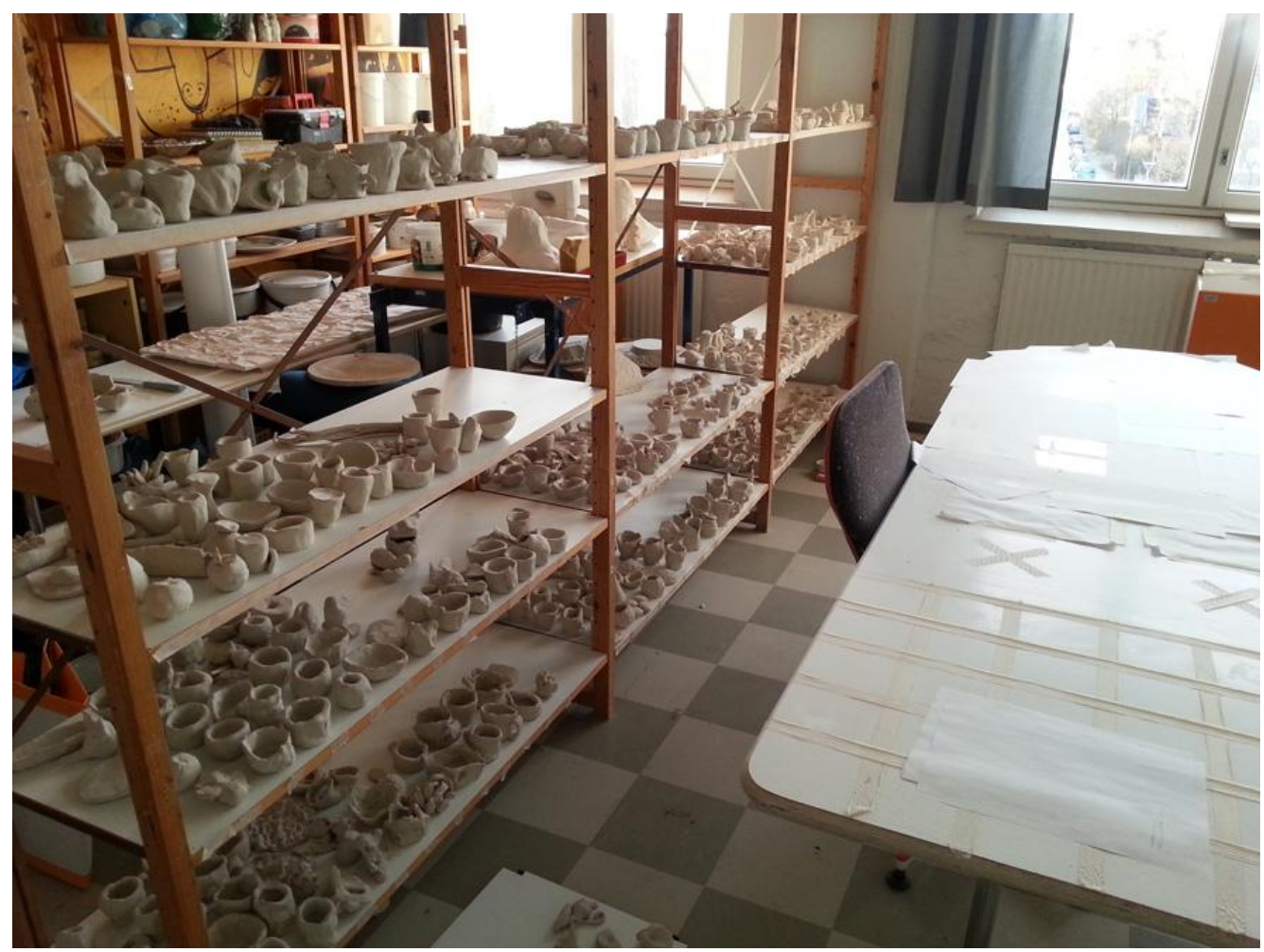

Figure 5: Shelves filling with clay objects, each of the 30 participants created 42 clay objects, resulting in a total of 1260 clay objects. Photo by Camilla Groth. 
The challenge involved in the designing of this experimental setting lies in combining a design study with a study in which physiological signals are recorded. In traditional design studies, the experimental protocols can be arranged according to the requirements of the design process, whereas when recording physiological signals, all kind of excess movements or differences in timing are potential sources of noise for the data. Further, the fact that the recommended minimum length for calculating frequency-domain HRV parameters from an electrocardiogram is 5 minutes has to be taken into account (Task Force 1996). In order to be able to compare the results from this study with our future EEG measurements, we included a 10-second long planning window with a fixation cross in the research setting between the task assignment and the actual execution of the design task. This will allow us to determine the brain correlates of the mental process during the planning of different tasks (copy, design, improvise) without the noise caused by the bodily movements during the actual processes.

At the beginning of the experiment, the participants reported their own level of expertise in drawing and clay forming on a scale of 0 to 100 and filled in the Profile of Mood questionnaire (POMS) both at the beginning and at the end of the research. In addition to the physiological recordings, the participants evaluated their subjective sleepiness using the 9-point questionnaire of the Karolinska Sleepiness Scale (Åkerstedt 1990) also and the task load experienced using NASA-TLX (Hart \& Staveland 1988) assessment tool five times during the research: at the beginning of the research day, and once after each of the prior described blocks. The experimental setting was followed by a stimulated recall interview during which the interviewer watched the video privately with each of the participants. The participants had the opportunity to reflect and comment on their work by probing certain feelings, inspirations, disturbances and pressures. The interviewer noted their emotional comments as well as remarks related to the work itself. The stimulated recall session was also video recorded for subsequent analysis. The results of the stimulated recall interviews will be reported in detail in later publications.

\section{Data analysis}

The heart rate variability (HRV) analysis of the electrocardiogram signal was performed using the Colibri software for R (version 3.2.2.; http://www.r-project.org/; R Core Team, 2015). The data was analysed with a segment length of $300 \mathrm{~s}$ without using segment overlap. Artefacts were detected using the modified method of Xu and Schuckers ( $X u$ 2001) and removed. From the HRV, the most common time-domain parameters, mean heart rate $(H R)$, standard deviation of RR intervals (SDNN), root mean square of the successive R-R differences (RMSSD) and the portion of the successive, consecutive R-R differences which differ by more than $50 \mathrm{~ms}$ (pNN50) were analysed. Further, we calculated in the frequencydomain the following parameters: the high frequency (HF) power, low frequency (LF) power, 
their ratio LF/HF, and the power of a specific frequency band of 0.01-0.08, which was recently shown to be more optimal for the analysis of electrocardiogram data in stress studies (Henelius 2014). Below, we are reporting only the strongest effects observed in the data.

\section{Results}

Of the total of thirty participants, the data of one participant was omitted due to technical difficulties. In addition, some of the data from two participants were omitted because of poor quality. The age range of the remaining 29 participants was $23-55$ years (mean 33.8; SD 8.6). Their self-reported level of drawing expertise on a scale of 0 to 100 was 83.2 (SD 21.9) and for clay forming 59.0 (SD 35.7). The subjective sleepiness values (KSS-values) did not change dramatically across the experiment (see Figure 6). The task load experienced (NASATLX values) during the course of the study, are presented in Figure 7, showing a clear rise in mental effort and frustration across the experimental session. The general factors of POMS mental states were not found to differ between the beginning and end of the experiment, but the enthusiasm experienced decreased from 2.6 at the beginning of the experiment to 1.9 by the end of the experiment.

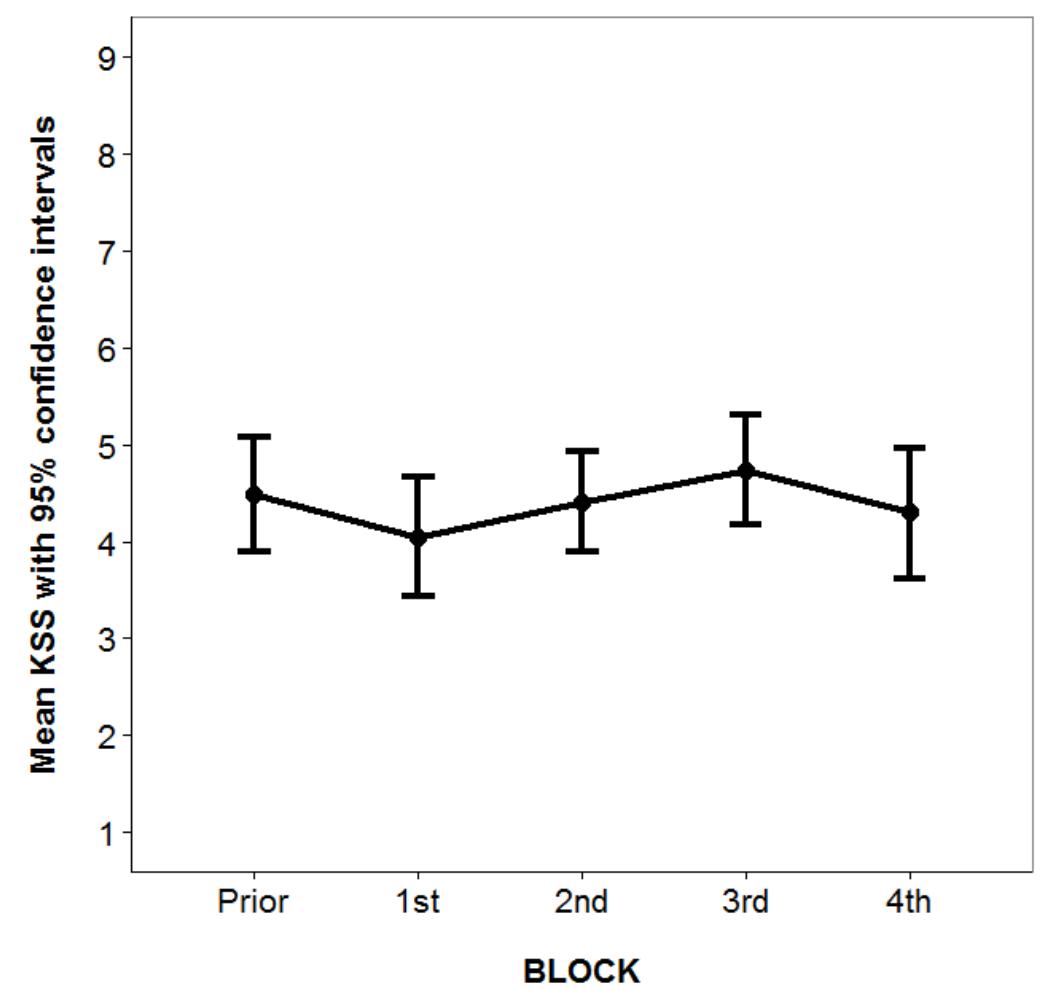

Figure 6. Karolinska sleepiness (KSS) values during the study. Scoring: $1=$ extremely alert; $9=$ very sleepy, great effort to keep alert, fighting sleep. 


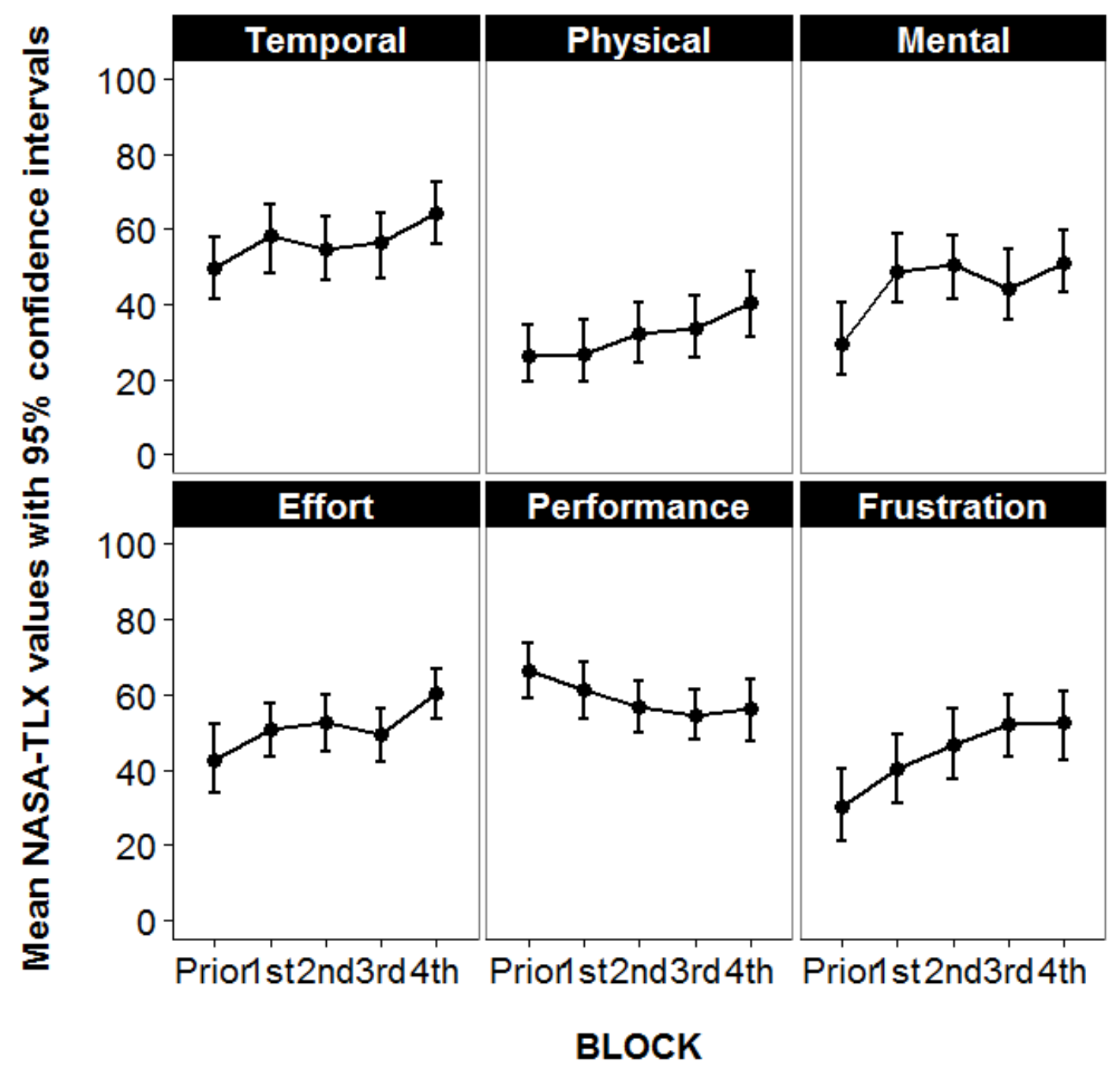

Figure 7. Task load experienced, NASA-TLX values during the study. A score of 100 represents high Temporal, Physical, Mental, and general Effort, high Frustration, and good Performance. 


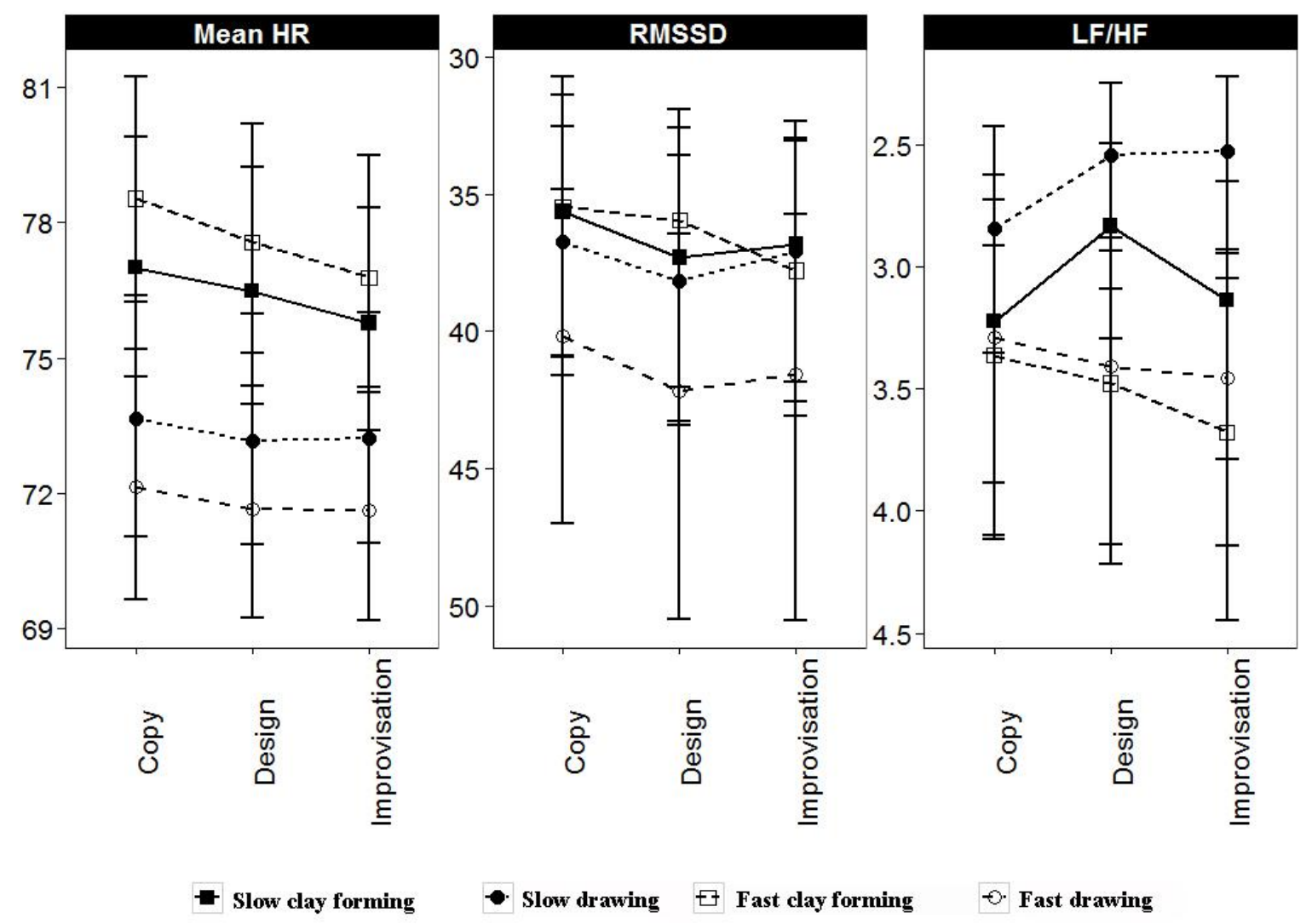

Figure 8. Mean HR, RMSSD and LF/HF ratio of the HRV signal with $95 \%$ confidence intervals presented across all participants in the three design tasks (copy, design, improvisation) separately for the fast and slow drawing and clay forming tasks.

When looking at the data from the mean HR values (see Figure 8, left column) across all participants, we can observe effects that are indicative of mainly bodily efforts. The mean $H R$, that is, the pulse in beats per minute across the 5-minute period, is a very sensitive measure of any physical effort or even posture. A clear effect of the material can be observed as a difference in physical activity according to the material: all tasks and all timings in the clay forming show a higher mean HR than those in the drawing tasks. The effect of the material (drawing vs. clay forming) is much stronger in the mean HR than any of the other two factors (task: copying, design, improvise or timing: fast or slow). Nonetheless, when separating the effects according to the fast and slow blocks, an interaction effect on mean HR between the material and the timing is observed: The physical effort is more pronounced in the fast blocks for the clay forming, but in the slow blocks in drawing. Indeed, 45 seconds to copy, design or improvise with clay seemed to be a very short time for the participants compared to the 3 minutes in the slow set-up, making the physical effort higher when the participants are trying to keep up with the required speed. 
The RMSSD of the cardiac signal measures the root mean square of the successive differences of the R-R-intervals in a 5-minute window. More variation, in other words, higher values of RMSSD, are indicative of a more relaxed mental state. In the RMSSD of the cardiac signal, we can observe that in the fast drawing tasks, the RMSSD is on average 40, while in the slow drawing and in the clay-forming tasks, it is around 35 (see Figure 8, middle panel). This is indicative of less stress and frustration in the fast drawing tasks compared to all other tasks, and especially in the design and improvisation tasks in fast drawing.

In the frequency-domain measures of the HRV signal, especially the LF/HF-ratio, the ratio between the low and high frequency power in the cardiac signal, an estimate of the mental efforts can be drawn. The low LF/HF-ratio indicating the highest amount of attentive effort and smallest amount of free cognitive resources available was generally observed in the slow tasks. Vice versa, the faster tasks seemed to yield higher values, even above 3.5, thus indicating larger free cognitive resources. This was especially evident in the design tasks, but even more strongly in the improvisation tasks for both materials (see Figure 8, right panel). This finding was further supported by calculating the pNN50, which was the lowest for copying, slightly higher for the design task and even higher for the improvisation task, indicative of the smallest amount of free cognitive resources available in the copying task, slightly more in the design task and the largest amount of free cognitive capacity available in the improvisation task. This finding was supported by the interviews given by the participants.

The above findings are evidence of differences between the two modalities, drawing and clay forming, highlighting the higher physical effort required by the clay forming compared to drawing - especially in the fast setup, which is exceptionally demanding. Interestingly, these effects are also observed when comparing the three tasks, copying, designing and improvising. The relevance of these findings for design and embodiment research is discussed below.

\section{Discussion}

Our research assessed the interaction between the modality (drawing and clay forming) and the task (copy, design and improvise) as well as the two timing setups (fast and slow). We have found evidence for a higher physical effort in the clay forming task compared to the drawing task in general. We also found evidence of higher physical effort in the fast timing setups compared to the slow timing setups. These two effects did not interact with the task, in other words, the same phenomenon concerning material as well as timing was observed across all three tasks.

The physiological parameters reflecting mental effort and cognitive resources are somewhat in parallel with the physical effort - higher effort in clay forming and especially fast clay 
forming - but also show interesting additional phenomena related to the task types. Most interestingly, the greatest amount of free mental resources was observed in the design and improvisation tasks in fast drawing compared to any other task. It may be concluded that free improvisation, especially involving drawing fast, improvised works, seems to be the most effective way of freeing mental resources. Similar benefits were also observed in fast, improvised working with clay. These effects when performing fast drawing tasks were also mentioned by the participants in the interviews, and we wish to direct our future analysis toward finding more detailed parallels between the physiological and interview data.

In addition, we are also very interested in the central nervous system activity during the copying, design and improvising tasks. There are several phenomena that could be observed as differences between these types of tasks and with respect to the modality (drawing or clay forming). A previous study by Kurk et al. (2014) revealed that both clay forming and drawing increased EEG gamma power in the right medial parietal lobe compared to general movement, and, further, that clay forming decreased right medial frontal gamma power and elevated theta power. In addition, the study by Belkofer et al. (2014) indicated that alpha rhythm may play an important role in drawing. In our future EEG study with the same paradigm, we are planning to investigate similar phenomena in our participants.

To conclude, we investigated the effects of material (drawing or clay forming) and task (copying, design and improvisation) from the point of view of both physical and mental processes. We found the physiological measurements reflecting physical effort to be highly correlated with both the material and the timing of the work. Namely, more physical effort was required by the clay forming tasks compared to the drawing tasks, and more physical effort was required when the task was performed more rapidly. These physical efforts did not have an interaction with the tasks; the physical effort was similar across copying, designing and improvisation.

We also found that the mental effort, while being partially connected to the physical effort, showed interesting and important specific effects. In detail, the mental stress levels were lowest for the designing and especially for the free improvisation tasks, particularly for drawing. These findings will receive more detailed accounts in the next phase of the research, when we will analyse the stimulated recall interviews that were conducted after each experiment. In addition, these interviews will provide us with information on how the participants experienced the mentally and physically demanding research setting. The preliminary results from the interviews reveal that even if the participants - who were professional designers - felt the experiment to be demanding, they also felt it to be interesting and possibly also capable of revealing something about their own manner of approaching design tasks as well as their thinking patterns when starting a creative work. Design is a human process that involves the whole mind-body connective system. Research on both the mental and bodily components in synchrony, that is, physiological 
measurements of the bodily functions combined with interviews and questionnaires of the mental components, are the only means to fully understand the complexities of design actions. These first results presented in this paper pave the way for further studies. The paradigm is well suited for EEG investigations, and our future studies will bring more detailed information on these tasks at the cortical level.

Future studies should be directed towards separating physical embodied effects (such as that of the material) in crossover designs from more mental embodiments (such as tasks with differing amounts of creativity or mental stress or effort). We believe that the measurement of physiological signals from cardiac effects to EEG can highlight the differences between the physical and mental characteristics in an embodied task such as drawing or clay forming according to specifications given concerning copying, designing new objects, and free improvisation with the material.

Acknowledgements: this research is funded by the Academy of Finland, project numbers: 265922 and 266125 . We would also like to thank all the participants of the study and the five students of the design department who acted as assistants during the measurements: Heli Juuti, Petra Leino, Anni-Marja Kuula, Anna-Miia Suominen and Eugenia Smirnova. Additionally we would like to acknowledge the two students from Helsinki University who conducted all the interviews: Anna Lohko and Aino Melkas.

\section{References}

Belkofer, C. M., Vaughan Van Hecke, A. \& Konopka, L. M. (2014) Effects of drawing on alpha activity: A quantitative EEG Study with implications for art therapy, Art Therapy, Journal of the American Art Therapy Association, 31 (2), pp. 61-68.

Borghia, M. \& Cimattic, F. (2010) Embodied cognition and beyond, Neuropsychologia, 48, pp. $763-$ 773.

Cain, P. (2010) Drawing: The enactive evolution of the practitioner, Bristol, UK. Intellect.

Cinaz, B., La Marca, R., Arnrich, B., \& Tröster, G. (2010) Monitoring of mental workload levels, In Proceedings of IADIS eHealth conference.

Damasio, A. (1999) The feeling of what happens: Body and emotion in the making of consciousness, New York: Hartcourt.

Damasio, A. (1994) Descartes' error: Emotion, reason, and the human mind, New York: Putnam.

Dourish, P. (2001) Where the Action is: The foundation of embodied interaction, Cambridge: MIT press.

Dunn, B.D., Galton, H.C., Morgan, R., Evans, D., Oliver, C., Meyer, M., Cusack, R., Lawrence, A.D. \& Dalgleish, T. (2010) Listening to Your Heart. How Interoception Shapes Emotion Experience and Intuitive Decision Making, Psychological Science, 21(12), pp. 1835-1844.

Gallace, A. \& Spence, C. (2008) The cognitive and neural correlates of "tactile consciousness": A multisensory perspective, Consciousness and cognition, 17 (1) pp. 370-407

Goel, V. (1995) Sketches of Thought, Cambridge, MA: the MIT Press.

Groth, C., Mäkelä, M. \& Seitamaa-Hakkarainen, P. (2015) Tactile augmentation: A multimethod for capturing experiential knowledge, Craft Research Journal, 6, (1), pp. 57-81. 
Groth, C. \& Mäkelä, M. (2014) The knowing body in material exploration Proceedings of The Art of Research V: Experience, Materiality, Articulation, International Conference 26-27 November 2014, Helsinki, Finland.

Groth, C., Mäkelä, M. \& Hakkarainen-Seitamaa P. (2013) Making Sense. FORMakademisk Journal, Vol 6, (2) pp. 1-12.

Hari, R \& Kujala M. M.(2009) Brain Basis of Human Social Interaction: From Concepts to Brain Imaging, Physiological Reviews. Vol 89, pp. 453-479.

Hart, S. G., \& Staveland, L. E. (1988) Development of NASA-TLX (Task Load Index): Results of empirical and theoretical research, Advances in psychology, Vol 52, pp. 139-183.

Henelius, A., Sallinen, M., Huotilainen, M., Müller, K., Virkkala, J. \& Puolamäki, K. (2014) Heart Rate Variability for Evaluating Vigilant Attention in Partial Chronic Sleep Restriction, Sleep, Vol 7, pp. 1257-1267.

Herbert, B.M., Pollatos, O., Flor, H., Enck, P. \& Schandry, R. (2010) Cardiac awareness and automatic cardiac reactivity during emotional picture viewing and mental stress, Psychophysiology, Vol 49, pp. 342-354.

Hornecker, E. (2005) A Design Theme for Tangible Interaction: Embodied Facilitation. In Gellersen et al. (eds.) ECSCW 2005: Proceedings of the 9th European Conference on Computer Supported Cooperative Work, September 18-22, Paris, France. pp. 23-43.

Hornecker, E., Buur, J. (2006) Getting a Grip on Tangible Interaction: A Framework on Physical Space and Social Interaction. Proceedings of SIGCHI 2006, Conference on Human Factors in Computing Systems. April 24-27, Montreal, Canada. ACM New York, USA. pp. 437-446.

Hummels, C., \& Van Dijk, J. (2015) Seven Principles to Design for Embodied Sensemaking. Proceedings of the 9th International Conference on Tangible, Embedded and Embodied Interaction (TEI'15), Stanford, CA. pp. 21-28

Höök, K. (2010) Transferring qualities from horseback riding to design. Proceedings of the $6^{\text {th }}$ NordiCHI: Extending boundaries, Reykjavik, Iceland, October 16-20. New York: ACM. pp. 226-235.

Johnson, M. (1987) The body in the mind, Chicago: Chicago University Press.

Johnson, M. (2007) The meaning of the body, Chicago: Chicago University Press.

Kantrowitz, A., Brew, A., Fava, M. Eds.(2011) Thinking through drawing: Practice into knowledge. Proceedings of an interdisciplinary symposium on drawing, cognition and education 28-29 October 2011. Teachers college, Columbia University, New York.

Kurk, K. A., Aravich, P. F., Deaver, S.P., DeBeus, R. (2014) Comparison of brain activity during drawing and clay sculpting: A preliminary qEEG study. Art Therapy. Journal of the American Art Therapy Association, 31 (2), pp. 52-60.

Lakoff, G. \& Johnson, M. (1999) Philosophy in the flesh: The embodied mind and its challenge to western thought, New York: Basic Books.

Luck, S.J. (2005) An Introduction to the Event-Related Potential Technique, Mass:The MIT Press.

Merleau-Ponty, M. (1962/2010) Phenomenology of Perception, London: Routledge.

Mäkelä, M. \& Löytönen, T (2015) Enhancing Material Experimentation In Design Education, in Vande Zande, R., Bohemia, E., \& Digranes, I. (2015) (Eds.) Proceedings of the 3rd International Conference for Design Education Researchers. June 28- July 1. Chicago, USA.

Noë, A. (2009) Out of our heads, New York: Hill and Wang.

Noë, A. (2004) Action in Perception. Cambridge: The MIT press.

Patel, K. (2008) Thinkers in the kitchen: Embodied thinking and learning in practice, Ann Arbour (MI): UMI dissertation services ProQuest. 
Poulsen, S. \& Thøgersen, U. (2011). Embodied design thinking: a phenomenological perspective, CoDesign: International Journal of CoCreation in Design and the Arts, 7 (1), pp. 29-44.

R Core Team (2015) R: A language and environment for statistical computing. R Foundation for Statistical Computing, Vienna, Austria. URL http://www.r-project.org/, (Accessed 16 Nov, 2015). Colibri can be downloaded from: www.github.com/bwrc/colibri (Accessed 16 Nov, 2015).

Rizzolatti, G., \& Craighero, L. (2004) The mirror-neuron system. Annu. Rev. Neurosci., Vol 27, pp. 169192.

Rompay, T. \& Ludden, G. (2013) Embodiment in design: on the embodied foundations of meaning and experience in product design. Conference proceeding at the $5^{\text {th }}$ IASDR 2013 Tokyo Conference. Tokyo, Japan.

Seitamaa-Hakkarainen, P. \& Hakkarainen, K. (2004) Visualization and sketching in design process. Design Journal, Vol 3, pp. 3-14.

Seitamaa-Hakkarainen, P., Huotilainen, M., Mäkelä, M. Groth, C. \& Hakkarainen, K. (2014) The promise of cognitive neuroscience in design studies. In Lim, Y.-K., Niedderer, K., Redström, J., Stolterman, E., \& Valtonen, A. (Eds.). (2014) Proceedings of DRS 2014: Design's Big Debates. Umeå, Sweden: Umeå Institute of Design, Umeå University. pp. 834-846.

Task Force of the European Society of Cardiology and the North American Society of Pacing and Electrophysiology. (1996) Guidelines, Heart rate variability. Standards of measurements, physiological interpretation, and clinical use. European Heart Journal, 17, pp. 354-381.

Trotto, A. \& Hummels, C.C.M. (2013) Designing in skills: nurturing personal engagement in design. In Proceedings of the 5th International Congress of International Association of Societies of Design Research (IASDR).

Varela, F.J. \& Thompson, E. \& Rosch, E. (1991) The Embodied Mind; Cognitive science and human experience, Cambridge: The MIT Press.

Veltman, J. A., \& Gaillard, A. W. K. (1998) Physiological workload reactions to increasing levels of task difficulty, Ergonomics, 4 1(5), pp. 656-669.

Witt, J., Kemmerer, D., Linkenauger, S. \& Culham, J. (2010) A Functional Role for Motor Simulation in Identifying Tools, Psychological Science, Vol 21, pp. 12-15.

Xu, X. \& Schuckers, S. (2001) Automatic detection of artifacts in heart period data, Journal of Electrocardiology, Vol 34 Suppl., pp. 205-210.

Åkerstedt, T. \& Gillbert, M. (1990) Subjective and objective sleepiness in the active individual. International Journal of Neuroscience, Vol 52, pp. 29-37.

About the Authors:

Marianne Leinikka M.Sc. (Eng.) Marianne Leinikkas' expertise is experimental work in physiological measurements, their technologies, and the analysis of physiological and brain data.

Minna Huotilainen Research professor, focusing on work-related neuroscience. Her interests include cognitive processes such as perception, memory, attention and the cognitive effects of sleep, work fatigue, attentive problems and embodied cognition. 
Pirita Seitamaa - Hakkarainen Professor of Craft Studies. Her main interest is to analyse expertise in design, the nature of the design process and the role of external representations such as drawings.

Camilla Groth Doctoral Candidate in the Department of Design. Her main interests lie in haptic experiences and embodied cognition in design practice.

Mimmu Rankanen Doctoral Candidate in the Department of Art. Rankanen is a qualified psychotherapist and art therapist, and her research interests include therapeutic, cognitive, emotional, embodied and material aspects of creative processes.

Maarit Mäkelä Associate Professor of Practice-Led Design Research. Mäkelä also works as an artist at the junction of ceramics and fine art. Her main interest is the creative process. 